\title{
BIOLOGICAL CONTROL OF WOOLLY APPLE APHID BY APHELINUS MALI IN AN INTEGRATED FRUIT PRODUCTION PROGRAMME IN NELSON
}

\author{
P.W. SHAW ${ }^{1}$ and J.T.S. WALKER ${ }^{2}$ \\ The Horticulture and Food Research Institute of New Zealand Ltd.,
${ }^{I}$ Nelson Research Centre, P O Box 220, Motueka
${ }^{2}$ Hawke's Bay Research Centre, Private Bag 1401, Havelock North
} ABSTRACT

Woolly apple aphid Eriosoma lanigerum (Hausmann) populations were monitored at the Appleby Research Orchard near Nelson (1994/ 1996) in two apple cultivars as part of an experimental Integrated Fruit Production programme which included the insect growth regulator insecticide tebufenozide. The aphid population increased dramatically during the first season in one cultivar ('Sturmer Pippin') from mid February and reached $90 \%$ shoot infestation by late summer. Parasitism of the aphid by the specific endoparasitoid,Aphelinus mali(Haldeman), was first recorded in late March 1995 and peaked at 13\% by the end of April 1995 when monitoring ceased. In the second season the parasitoid was present from early summer and $>80 \%$ parasitism was recorded by late April 1996. Aphid control was achieved without the need for specific aphicide sprays. The results indicate the potential for biological control of woolly apple aphid by A. mali within a selective insecticide programme.

Keywords: woolly apple aphid,Eriosoma lanigerum, biological control, Aphelinus mali, integrated fruit production

\section{INTRODUCTION}

Woolly apple aphid (WAA), Eriosoma lanigerum (Hausmann), is a common pest of apple occurring throughout the apple growing regions of the world. In New Zealand, it is the only aphid species of economic importance on apples (Ferro 1976). The aphid forms densely packed colonies, covered with a white, waxy, filamentous secretion, on aerial parts of apple trees and occasionally on the roots. The feeding activity of the aphids causes galls to form on the woody tissue and, on young lateral shoots, buds can be destroyed. The calyces of apples may also be infested by aphid colonies resulting in contamination with honeydew and sooty mould.

Aphelinus mali (Haldeman) (Hym. Aphelinidae) is a specific endoparasitoid of woolly apple aphid. It has been introduced as a biological control agent from its native home, North America, into apple growing regions throughout the world and is considered to be the most important parasitoid of WAA (Brown and Schmitt 1994). A. mali was introduced into New Zealand from North America in 1921 (Cameron et al. 1989) with initial releases in the Nelson district. By 1925 it was widespread through New Zealand, almost completely eliminating WAA in orchards at that time (Cottier 1935; DSIR files, Auckland). However, WAA continues to be a problem in commercial orchards and insecticide sprays are normally applied to control it. The routine use of broad-spectrum organophosphorous (OP) insecticide sprays to control major quarantine pests, particularly leafroller and codling moth, also provides considerable suppression of the aphid and parasitoid populations and so minimises the effectiveness of biological control. In the absence of pesticides, WAA is rarely a serious pest of apples in New Zealand and is effectively controlled by A. mali (Collyer and van Geldermalsen 1975; Cameron et al. 1989). 
The recent introduction of selective insect growth regulator (IGR) insecticides has increased the potential for biological control of some important orchard pests including WAA. Initial research results from the evaluation of a regional integrated fruit production (IFP) programme have been reported last year (Walker et al. 1995). This paper documents the effectiveness of $A$. mali for biological control of WAA over two seasons in Nelson in an experimental IFP programme, which used the IGR insecticide, tebufenozide (Mimic).

\section{METHODS}

The study was conducted over two seasons $(1994 / 95,1995 / 96)$ in a 0.6 hectare block of mature 'Sturmer Pippin' and 'Granny Smith' trees at the Appleby Research Orchard, near Nelson. Use of the insecticide azinphosmethyl continued until 2 December 1994 in the 'Sturmer Pippin' while chlorpyrifos was last applied to the 'Granny Smith' block on 6 January 1995. The tebufenozide programme commenced in both blocks on 26 January 1995. Five applications of tebufenozide $(260 \mathrm{~g} / \mathrm{ha}$ in 2000 litres of water) were made at 2-3 weekly intervals for the remainder of that season while there were just four applications applied during the 1995/96 season. This insecticide and the primary fungicides used, metiram and captan, have been found to be non-toxic to A. mali at field rates (Bradley and Walker unpublished data).

\section{Woolly apple aphid population assessment}

Extension shoots were examined for the presence of WAA colonies and the percentages of infested shoots were recorded in each of two, five minute time searches for each cultivar. Approximately 90-100 shoots were observed during each of the five minute time searches. In addition, the number of aphid colonies found on up to ten, 20 $\mathrm{cm}$ sections of randomly-selected infested shoots were counted to provide a more detailed estimate of aphid infestation. Monitoring was carried out at 2-3 weekly intervals. In the 1994/95 season, monitoring did not start before February due to the late commencement of the selective insecticide programme. Seven time searches were carried out between February and the end of April and in the 1995/96 season, there were twelve between November and late April.

\section{Woolly apple aphid parasitism}

If present, aphid colonies from up to ten infested shoot sections $(20 \mathrm{~cm})$ were examined individually and the number of intact and mummified (black pre-pupal and pupal stages of $A$. mali) parasitised aphids from each colony on each shoot was recorded separately. This was done by carefully brushing all aphids in a colony on to a Petri dish with a little ethyl alcohol and then counting them using a grid and a binocular microscope. It was not practical to detect parasitism of aphids in the early stages of development.

\section{Harvest assessment}

Fruit infestation by WAA at harvest was recorded by cutting and examining 100 fruit from each of 10 (1995) to 15 (1996) trees in each variety. In the 1996 assessment, the incidence of WAA parasitism within the fruit was also recorded.

\section{RESULTS AND DISCUSSION}

WAA infestation and the level of parasitism over the two seasons for the cvs. 'Sturmer Pippin' and 'Granny Smith' blocks are shown in Table 1.

The insecticide chlorpyrifos is highly toxic to A. mali (Bradley and Walker unpublished data) and its use in the 'Granny Smith' block until January 1995 probably limited WAA and $A$. mali establishment and activity in the block during that season. The absence of OP sprays for the remainder of that season resulted in a rapid increase in the level of WAA-infested shoots, and the mean number of colonies per shoot, peaking at 90\% of infested shoots in the 'Sturmer Pippin' trees with almost 5 colonies per shoot by 30 March. Parasitism recording commenced in March 1995 and the level of parasitism increased slowly in response to the increasing WAA population, reaching $13 \%$ of aphidinfested shoots in the 'Sturmer Pippin' when monitoring finished on 28 April. At that time, these trees were heavily infested with WAA. The number of WAA in the 'Granny Smith' block was very low, probably due to the application of chlorpyrifos in January 
1995 and a lower initial aphid population. WAA was found only in the last two time searches in April 1995 and parasitism was not detected.

TABLE 1: Percentage WAA-infested shoots, the mean number of aphid colonies and aphids per shoot and percent parasitism by $A$. mali in aphids from 'Sturmer Pippin' ('Granny Smith' in brackets) IFP block for 1994/95 and 1995/96 season.

\begin{tabular}{lccccc}
\hline $\begin{array}{l}\text { Sampling } \\
\text { date }\end{array}$ & $\begin{array}{c}\text { Infested } \\
\text { shoots } \\
(\%)\end{array}$ & $\begin{array}{c}\text { Colonies per } \\
\text { infested } \\
\text { shoot }\end{array}$ & $\begin{array}{c}\text { Aphids per } \\
\text { infested } \\
\text { shoot }\end{array}$ & $\begin{array}{c}\text { Parasitism } \\
\%\end{array}$ & $\begin{array}{c}\text { Parasitism } \\
\text { SEM }\end{array}$ \\
\hline
\end{tabular}

1995

\begin{tabular}{lrlllllllll} 
Feb 3 & 1.3 & $(0)$ & 1.5 & & & & & & & \\
Feb 17 & 37.4 & $(0)$ & 2.0 & & & & & & & \\
Mar 3 & 57.9 & $(0)$ & 2.7 & & & & 2.7 & & & \\
Mar 20 & 73.8 & $(0)$ & 4.7 & & 75.6 & & 2.8 & & 1.3 & \\
Mar 30 & 90.0 & $(0)$ & 4.6 & & 45.7 & & 1.1 & & 0.5 & \\
Apr 13 & 75.9 & $(0.4)$ & 4.5 & $(1.0)$ & 73.1 & $(3.0)$ & 8.2 & $(0)$ & 2.2 & $(0)$ \\
Apr 28 & 76.0 & $(0.4)$ & 4.5 & $(1.0)$ & 101.3 & $(11.0)$ & 13.1 & $(0)$ & 4.0 & $(0)$ \\
& & & & & & & & & & \\
1995/96 & & & & & & & & & & \\
Nov 15 & 3.0 & $(0.8)$ & 1.5 & $(1.0)$ & & & & & & \\
Nov 30 & 7.5 & $(0.6)$ & 1.1 & $(1.0)$ & 1.3 & $(1.0)$ & 37.5 & $(0)$ & 18.3 & $(0)$ \\
Dec 13 & 11.7 & $(3.2)$ & 1.3 & $(1.0)$ & 6.8 & $(18.5)$ & 20.6 & $(0)$ & 9.4 & $(0)$ \\
Jan 3 & 10.5 & $(0)$ & 1.4 & & 13.8 & & 23.2 & & 8.3 & \\
Jan 19 & 4.6 & $(0)$ & 1.2 & & 13.6 & 42.7 & & 10.7 & \\
Feb 1 & 7.0 & $(0)$ & 1.2 & & 25.1 & & 44.7 & & 6.3 & \\
Feb 14 & 13.6 & $(2.2)$ & 1.2 & $(1.3)$ & 29.6 & $(25.0)$ & 35.1 & $(16.0)$ & 8.3 & $(5.5)$ \\
Feb 27 & 8.8 & $(1.8)$ & 1.4 & $(1.7)$ & 35.2 & $(48.0)$ & 42.3 & $(31.3)$ & 7.1 & $(8.4)$ \\
Mar 13 & 16.8 & $(1.1)$ & 1.4 & $(1.5)$ & 11.6 & $(21.5)$ & 62.9 & $(34.9)$ & 10.0 & $(13.2)$ \\
Mar 27 & 4.8 & $(0)$ & 1.9 & & 33.7 & & 52.5 & & 7.5 & \\
Apr 15 & 3.5 & $(0)$ & 1.2 & & 10.4 & & 44.2 & & 10.3 & \\
Apr 24 & 4.5 & $(0.5)$ & 1.1 & $(2.0)$ & 15.3 & $(48.0)$ & 83.0 & $(64.6)$ & 4.3 & $(3.6)$ \\
\hline
\end{tabular}

A $2 \%$ mineral oil spray was applied at bud burst the following spring (1995) and no specific sprays were applied for WAA all season. Aphid monitoring revealed that there was considerable parasitism $(37 \%)$ by late November in the 'Sturmer Pippin' trees and the percentage of shoots infested with WAA population had declined compared to the previous season. The percentage of infested shoots continued to fluctuate at much lower levels (3-17\%) than in 1994/95, (Table 1) with the peak again occurring in March. The mean number of colonies per shoot was also reduced, not exceeding 2 for the whole season. High levels of parasitism (20-83\%) were recorded in the 'Sturmer Pippin' throughout the season and this provided an acceptable level of aphid control. The level of parasitism is related to colony size (Mueller et al. 1992) with generally high parasitism occurring in smaller colonies with fewer survivors. Aphids in a small colony are more accessible to the parasitoid than those in the centre of larger colonies, which are protected from parasitoid attack due to the dense crowding of aphids. The results from this study supported this trend, indicating a significantly higher proportion of aphids in small colonies were parasitised than in larger ones $\left(\mathrm{R}^{2}=77.1 \% ; \mathrm{P}<0.001\right)$ (Fig. 1). The analysis was undertaken using data from 'Sturmer Pippin' trees in 1996. Most of the colonies examined were small $(<10$ aphids) and these tended to be heavily parasitised. The WAA population in the 'Granny Smith' block was higher at times during the 1995/96 than in 1994/95 but the parasitoid was present, even with low host numbers and parasitism peaked at $64 \%$ in late April 1996. 


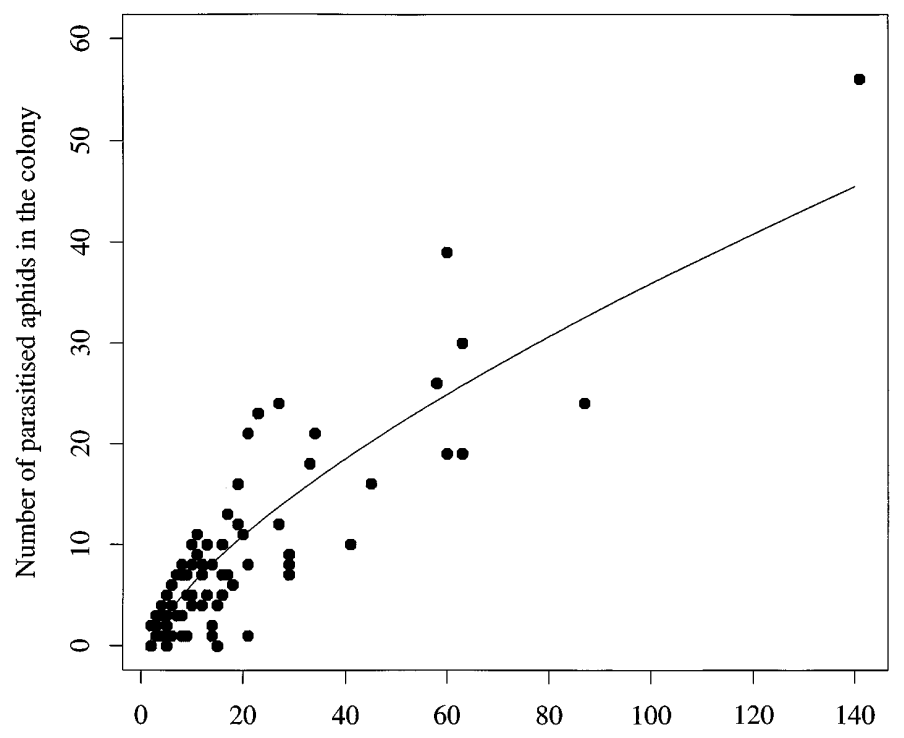

Total number of aphids in the colony

FIGURE 1: Regression analysis of the relationship between the number of parasitised aphids in a colony and the total number of aphids in a colony from 'Sturmer Pippin' 1996 (n=99).

\section{Harvest assessment}

The 'Sturmer Pippin' fruit were harvested on 23 March 1995 and the level of infestation by WAA was $2.9 \%$, while the 'Granny Smith' fruit were harvested on 7 April and had no infestation. Harvest dates and infestation levels for 'Sturmer Pippin' and 'Granny Smith' in 1996 were 22 March, 1.5\% and 9 April, $0.9 \%$ respectively. The 'Sturmer Pippin' result was a 50\% reduction in fruit infestation compared to the previous season. In 1996, the percentage of parasitism was recorded for aphids infesting the fruit. Parasitism in 1996 was similar (32-43\%) in both cultivars.

\section{CONCLUSION}

A. mali has demonstrated its ability to establish and regulate WAA populations over two seasons, in a tebufenozide spray programme in Nelson, without the need for intervention with specific aphicide sprays. In addition to tebufenozide, A. mali is tolerant of a number of important orchard pesticides, such as metiram and captan (Bradley and Walker unpublished data). It will therefore be an important component in an IFP programme based on selective insecticides. Control of other insect fruit pests, particularly mealybugs and scale insects, by optimising the use of their biological control agents and using selective pesticides, will also be necessary for the development of an effective IFP system for New Zealand apple orchards. This is an important aspect of current research.

\section{ACKNOWLEDGEMENTS}

We wish to thank Anne Chilcott for her assistance with field work and data collation. This research was supported, in part, by funding from ENZA New Zealand (International). 


\section{REFERENCES}

Brown, M.W. and Schmitt, J.J., 1994. Population dynamics of woolly apple aphid (Homoptera: Aphididae) in West Virginia apple orchards. Environ. Entomol. 23: 1182-1188.

Cameron, P.J., Hill, R.L., Bain, J. and Thomas, W.P., 1989. A Review of Biological Control of Invertebrate Pests and Weeds in New Zealand 1874 to 1987. Technical Communication No. 10. CAB International Institute of Biological Control (CIBC).

Collyer, E. and van Geldermalsen, M., 1975. Integrated control of apple pests in New Zealand. 1. Outline of experiment and general results. N.Z. J. Zool. 2:101-134.

Ferro, D.N., 1976. Pp. 43-43 In: New Zealand Insect Pests. Lincoln University College of Agriculture, Canterbury, New Zealand.

Mueller, T.F., Blommers, L.H.M. and Mols, P.J.M., 1992. Woolly apple aphid (Eriosoma lanigerum Hausm., Hom., Aphidae) parasitism by Aphelinus mali Hal.(Hym., Aphelinidae) in relation to host stage and host colony size, shape and location. J. Appl. Ent. 114: 143-154.

Walker, J.T.S., Lo, P.L. Bohm, V.F., Shaw, P.W. and White, V., 1995. Development of an Integrated Fruit Production Programme for Hawkes Bay and Nelson. HortResearch Client Report No. 95/207. 